OPEN ACCESS

Edited by:

Lee Mark Wetzler,

Boston University School of

Medicine, USA

Reviewed by:

Bruno Lucas,

CNRS, France

Nejat K. Egilmez,

University of Louisville, USA

*Correspondence:

Bruce D. Mazer,

Translational Research in Respiratory

Diseases Program, Centre for

Translational Biology (CTB), The

Research Institute of the McGill University Health Centre, Room EM3.2219, 1001 Decarie Blvd.,

Montreal, QC H4A 3J1, Canada

bruce.mazer@mcgill.ca

tPresent address:

Amir H. Massoud,

Division of Immunology Research,

Boston Children's Hospital, Boston,

MA, USA

Specialty section:

This article was submitted to Immunotherapies and Vaccines, a section of the journal Frontiers in

Immunology

Received: 16 July 2015

Accepted: 28 August 2015 Published: 11 September 2015

Citation:

Kaufman GN, Massoud AH, Dembele M, Yona M, Piccirillo CA and Mazer BD (2015) Induction of regulatory $T$ cells by intravenous immunoglobulin: a bridge between adaptive and innate immunity.

Front. Immunol. 6:469. doi: 10.3389/fimmu.2015.00469

\section{Induction of regulatory $T$ cells by intravenous immunoglobulin: a bridge between adaptive and innate immunity}

\author{
Gabriel N. Kaufman ${ }^{1}$, Amir H. Massoud ${ }^{1,2+}$, Marieme Dembele ${ }^{1}$, Madelaine Yona ${ }^{1}$, \\ Ciriaco A. Piccirillo ${ }^{3}$ and Bruce D. Mazer ${ }^{1,4 *}$
}

1 Translational Research in Respiratory Diseases Program, The Research Institute of the McGill University Health Centre, Montreal, QC, Canada, ${ }^{2}$ Laboratory of Cellular and Molecular Immunology, University of Montreal Hospital Research Centre, Montreal, QC, Canada, ${ }^{3}$ Infectious Diseases and Immunity in Global Health Program, The Research Institute of the McGill University Health Centre, Montreal, QC, Canada, ${ }^{4}$ Department of Pediatrics, Faculty of Medicine, McGill University, Montreal, QC, Canada

Intravenous immunoglobulin (IVIg) is a polyclonal immunoglobulin G preparation with potent immunomodulatory properties. The mode of action of IVIg has been investigated in multiple disease states, with various mechanisms described to account for its benefits. Recent data indicate that IVIg increases both the number and the suppressive capacity of regulatory $T$ cells, a subpopulation of $T$ cells that are essential for immune homeostasis. IVIg alters dendritic cell function, cytokine and chemokine networks, and T lymphocytes, leading to development of regulatory T cells. The ability of IVIg to influence Treg induction has been shown both in animal models and in human diseases. In this review, we discuss data on the potential mechanisms contributing to the interaction between IVIg and the regulatory T-cell compartment.

Keywords: intravenous immunoglobulin, regulatory T cell, dendritic cell, autoimmunity, immune modulation, cytokine

\section{Introduction}

\section{Intravenous Immunoglobulin}

Intravenous immunoglobulin (IVIg) is prepared from polyclonal immunoglobulin G (IgG) purified from pooled plasma samples of several thousand healthy donors. IgG has been the standard treatment for primary immunodeficiency diseases since Bruton's identification of a patient with agammaglobulinemia in the early 1950s (1). However, Imbach et al. (2), in the early 1980s, demonstrated that administration of high doses of human polyclonal IgG in children with immune deficiency who concomitantly suffered from immune thrombocytopenic purpura (ITP) had a dramatic increase in platelet counts. Since then, there has been a progressive increase in the use of IVIg in patients

\footnotetext{
Abbreviations: APC, antigen-presenting cell; CLRs, C-type lectin receptors; DC, dendritic cell; EAE, experimental autoimmune encephalitis; $\mathrm{F}(\mathrm{ab})$, fragment antibody-binding region; $\mathrm{Fc}$, fragment crystallizable region; Fc $\gamma \mathrm{R}, \mathrm{Fc}$-gamma receptor; GFP, green fluorescent protein; IgG, immunoglobulin G; ITAM, immunoreceptor tyrosine-based activation motif; ITIM, immunoreceptor tyrosine-based inhibition motif; ITP, immune thrombocytic purpura; IVIg, intravenous immunoglobulin; KS, Kawasaki syndrome; MHC, major histocompatibility complex; NK, natural killer; saIVIg, sialylated fraction of IVIg; TCR, $\mathrm{T}$-cell receptor; Treg, regulatory $\mathrm{T}$ cell.
} 
with a wide variety of autoimmune and inflammatory disorders. IVIg is used as a primary treatment for ITP, Kawasaki Syndrome (KS), Guillain-Barré syndrome, myasthenia gravis, chronic inflammatory demyelinating polyneuropathy, systemic lupus erythematosus, and other autoimmune and neurologic disorders (3). IVIg is commonly used in the prevention or treatment of neonatal sepsis. Rationally, those infants who are premature or suffer from very low birth weights should benefit from the immune supplementation provided by IVIg. However, large randomized clinical trials have failed to show consistent benefit in terms of prevention or outcomes from septic episodes (4-6). Novel preparations enriched in IgM may have some promise, but to date results are inconsistent $(7,8)$.

Intravenous immunoglobulin is now the most commonly prescribed plasma-based product worldwide (3, 9). This increased use raises questions regarding the long-term viability of this therapy. Considering the high cost and limited availability of this resource, it is imperative to investigate the underlying mechanisms of IVIg in order to tailor the anti-inflammatory response obtained by treatment, allowing for better therapies for inflammatory and autoimmune diseases. Furthermore, this can lead to the development of non-plasma-derived drugs with similar therapeutic benefits.

Many mechanisms explaining the immune-regulatory actions of IVIg have been postulated, including modulation of inhibitory Fc-gamma receptor $(\mathrm{Fc} \gamma \mathrm{R})$ expression, blockade of activating $\mathrm{Fc} \gamma \mathrm{R}$ on antigen-presenting cells (APCs), interference with cytokine production, inhibition of cell activation, or induction of apoptosis in a variety of immune cells, including dendritic cells (DCs), macrophages, natural killer (NK) cells, and T and B lymphocytes $(3,9,10)$. However, a key factor in immune modulation is the ability to counter inflammatory responses with regulatory cells. In this review, we will explore the links between IVIg and regulatory $\mathrm{T}$-cell responses.

\section{Regulatory T Cells}

Regulatory T cells (Treg) were initially described in the 1990s as a specialized subpopulation of $\mathrm{T}$ cells that maintain immune system homeostasis and tolerance to self-antigens $(11,12)$. The transcription factor forkhead box P3 (FOXP3) is considered the marker of choice for this cell (13). FOXP3 is a master-switch transcription factor: its expression modifies $\mathrm{T}$ cells toward a regulatory phenotype, enabling many of the anti-inflammatory functions of Treg (14). The fundamental property that defines Treg is their ability to transfer immune suppression in vivo from one animal to another or in vitro from one cell culture to another (15). Based on their developmental or functional differences, Treg are categorized into two main populations: naturally occurring Treg that are generated in the thymus (tTreg) and peripherally induced Treg ( $\mathrm{p}$ Treg) generated in peripheral lymphoid tissues from non-Treg precursor $\mathrm{CD}^{+}$cells. While Treg are $\mathrm{CD}^{+}$ T-effector cells with characteristic FOXP3 expression, this is not sufficient to define a cell population as Treg: single-cell flow cytometric sorting experiments have shown the importance of elevated expression of the high-affinity IL-2 receptor, CD25, as a hallmark of Treg (16). Other markers, including HLA-DR, GARP, and low CD127 expression, along with CTLA-4 and Helios, are not entirely consistent or reliable and depend on the activation state of the cell (17). Recent work by Bin Dhuban et al. (18) has identified two cell-surface Treg markers: TIGIT, a novel CD28related protein, and FCRL3, an Fc-receptor-like glycoprotein, which allow for high-consistency detection of Treg in human peripheral blood mononuclear cells (PBMCs).

Pre-clinical studies have shown that freshly isolated or ex vivoexpanded Treg can confer immunological tolerance in subjects with autoimmune and inflammatory disorders $(19,20)$. However, human Treg infusion therapy has been difficult to implement, and relatively few clinical trials have been initiated (21). Therefore, developing new therapeutic approaches with the capability to modulate the immune system through activation and/or expansion of Treg has been the subject of many recent studies. Several therapeutic immunosuppressive compounds, including rapamycin (22) and glucocorticoids (23), have been identified as promoting the expansion or suppressive activity of Treg.

Intravenous immunoglobulin has been proposed as a treatment that can promote development or activation of Treg in autoimmune diseases (24). Herein, we provide an overview examining if IVIg indeed influences induction of Treg in the context of different inflammatory and autoimmune conditions and discuss mechanisms underlying Treg induction by IVIg.

\section{Evidence for the Action of IVIg in the Promotion of Treg in Human Clinical Trials}

An early clue suggesting regulatory effects of IVIg was the observation that $\mathrm{T}$ cells, purified from IVIg-treated individuals, had significant suppressive effects when cultured with proliferating $\mathrm{T}$ and $\mathrm{B}$ cells (25). Subsequent studies demonstrated that IVIg therapy was associated with enhanced mitogen-induced "suppressor T-cell function" in rheumatoid arthritis (26), ITP (27), and pediatric acquired immune deficiency syndrome (28). More recently, Kessel et al. (29) demonstrated that in vitro culture of IVIg with peripheral T cells led to increases in intracellular TGF$\beta$, IL-10, and FOXP3 expression as well as improvement in their suppressive functions when cocultured with effector $\mathrm{T}$ cells.

$\mathrm{T}$ cells from patients treated with IVIg have been examined for increases in Treg. In Guillain-Barré syndrome, IVIg therapy increases the expression of FOXP3 and the production of inhibitory cytokines in Treg (30). In systemic lupus erythematosus, IVIg-treated patients show significant increases in Treg numbers; moreover, IVIg appeared to convert naive FOXP3- ${ }^{-} \mathrm{CD} 25^{-}$into activated $\mathrm{FOXP}^{+}{ }^{+} \mathrm{CD} 25^{+}$Treg (31). Consistently, IVIg therapy of EGPA patients increased FOXP3 ${ }^{+}$Treg numbers and production of IL-10 in $\mathrm{CD}^{+} \mathrm{T}$ cells (32). In mononeuritis multiplex, a peripheral neuropathy, steroid unresponsive patients treated with IVIg exhibit enhanced populations of Treg (33).

\section{Mechanisms of Action of IVIg in KS}

Kawasaki syndrome is an acute systemic vascular inflammation, primarily affecting children. A single IVIg treatment is generally successful in reducing fever and associated disease manifestations (34). Extensive work has focused on characterizing the IVIginduced Treg response in KS. Burns et al. (35) investigated the link between TNF- $\alpha$ and IVIg therapy in KS, hypothesizing that 
TNF- $\alpha$ inhibition may decrease cell activation. They determined that infliximab treatment does not interfere with Treg induction by IVIg, finding that the expansion of $\mathrm{CD} 14^{+} \mathrm{CD} 86^{+}$tolerogenic DC correlated with increased Treg after IVIg treatment. They postulate that the IVIg-induced Treg pool secretes IL-10 and responds to the Ig heavy-chain Fc region.

In a subsequent study from the same group, Franco et al. (36) investigated the specificity of IVIg-induced Treg in subacute KS patients. IVIg treatment induced a subset of Treg that expressed high levels of CTLA-4, and secreted IL-10, but not TGF- $\beta$. This Treg expansion appeared to be key to controlling vascular inflammation in KS. Cloned Treg expanded ex vivo only responded to soluble IgG Fc and not to $\mathrm{F}(\mathrm{ab})^{\prime 2}$ fragments, indicating that these Treg were Fc-specific and that the mechanism was likely T-cell receptor (TCR)-dependent. Coculture experiments revealed that the Fc region of IgG was presented in a major histocompatibility complex (MHC)-restricted, TCR-mediated manner by EBV-transformed B cells. Further investigation of the Fc peptide specificities of the tTreg population revealed similar profiles in both IVIg-treated KS patients and in healthy controls, suggesting that Treg responses are functionally inadequate in KS and that this can be reversed by IVIg (37).

In $\mathrm{KS}$ patients, IVIg treatment enhances the expression of genes related to Treg activation, including FOXP3, CTLA4, GITR, and TGFB1. The expression levels of these genes were significantly lower in KS patients prior to treatment than in healthy controls $(38,39)$. Ni et al. (40) examined the mechanisms of Treg dysfunction in KS, focusing on microRNAs (miR). While acute KS patients had lower Treg numbers and decreased Treg marker expression, IVIg treatment increased Treg numbers and FOXP3, CTLA4, and GITR gene expression. Treg from untreated KS have down-regulated miR-155 and miR-21 microRNAs; miR-155 down-regulation leads to increased SOCS1 signaling, decreased STAT-5 signaling, and miR-31 microRNA overexpression. IVIg treatment reversed these effects, restoring the SOCS1/STAT5 balance and decreasing miR-31 expression. FOXP3-dependent miR-155 inhibited SOCS1, and STAT3 suppressed miR-21, which down-regulated FOXP3. IVIg treatment of KS patients lowered elevated IL-6 and pSTAT3, restoring miR-21 levels, providing an explanation for the increase in Treg numbers following IVIg infusion.

\section{Modulatory Effects of IVIg in Animal Models of Inflammatory Disorders via Treg Expansion and Induction}

\section{Role of IVIg in Experimental Autoimmune Encephalomyelitis}

In experimental autoimmune encephalomyelitis (EAE), an antigen-driven murine model of multiple sclerosis, IVIg treatment reduced the disease severity scores, promoted the expansion of Treg and enhanced their suppressive capacity, both in vivo and in vitro (39). Importantly, administration of IVIg failed to confer protection in EAE mice that were depleted of Treg prior to treatment, suggesting a critical role of endogenous Treg in conferring protection by IVIg. In line with these findings, Okuda et al. (41) replicated the effects of IVIg in EAE and showed that sulfonated IVIg was effective in increasing the frequency of Treg.

A potential target for IVIg in EAE is NK cells. NK cells have a wide variety of immunomodulatory functions, interacting with B cells, DC, and Treg $(42,43)$. Chong et al. (44) hypothesized that in IVIg-treated subjects, NK cells suppress disease by regulating inflammatory $\mathrm{T}$-cell responses. Using an EAE model, they demonstrated that IVIg treatment blocks EAE development and reduces demyelination by diminishing IL-17 and IFN- $\gamma$. NK cell depletion by anti-asialo GM1 antibody resulted in the loss of IVIg-mediated protection, and adoptive transfer of IVIg-treated NK cells was as equally protective as IVIg treatment. IVIg-treated NK cells induced CD $4^{+}$Foxp $^{+}$Treg in spleen and draining lymph nodes, which were suppressive to antigen-specific effector $\mathrm{T}$ cells in ex vivo proliferation assays. Upon further investigation using an in vitro coculture system, Treg induction was determined to depend on IL- 2 and TGF- $\beta 1$ production by NK cells. Chong et al. posit that IVIg may promote redistribution of NK cells in peripheral tissues, depending on the inflammatory stimulus. Since NK cells modulate their chemokine receptor expression to facilitate migration to local and peripheral sites of inflammation (45), IVIg may increase NK cell homing to inflammatory microenvironments and secondary lymphoid organs, where they can induce Treg. NK cell costimulatory molecule expression may also drive Treg induction: IL-2 and plate-bound anti-CD16 treatment up-regulate CD86 and OX-40 ligand on NK cells in vitro (46). CD86 has been implicated in Treg generation (47), and OX-40 ligand can deliver a survival signal to Treg (48).

\section{Treg Induction in Allergen-Driven and Autoimmune Models}

We have recently demonstrated, using an ovalbumin-driven murine model of allergic airway disease, that therapeutic administration of IVIg attenuated airway hyper-reactivity (AHR) and alleviated airway inflammation. This was accompanied by induction of highly suppressive, antigen-specific Treg derived from pre-existing T-effector cells. Treg induction was dependent on the interaction of IVIg with CD11c ${ }^{+}$ DC (49). Similarly, in a murine model of ITP, IVIg increased thymic and splenic Treg, accompanied by restoration of platelet counts (50).

Different dosing regimens have been used for IVIg to increase Treg (51). Our laboratory, as well as most other groups, uses highdose IVIg ( $2 \mathrm{~g} / \mathrm{kg})$, which is analogous to the immunomodulatory dose used in clinical practice (49). Other studies have used typical antibody-replacement doses of $400-800 \mathrm{mg} / \mathrm{kg}$ (52). Ramakrishna et al. (53) reported an anti-inflammatory effect using extremely low-dose IVIg $(187.5 \mathrm{mg} / \mathrm{kg})$ in a HSV-mediated encephalitis murine model, which was felt to be dependent on enhancement of Treg. This dose range is rarely used clinically, making this work difficult to apply to standard practice. In addition, work from our laboratory and others $(38,54)$ suggests that a minor fraction of IVIg is required for some, but not all immunomodulatory effects. This will be discussed in more detail below. 


\section{Mechanisms of Action of IVIg in Induction of Treg}

The mechanisms by which IVIg induces Treg may involve direct interaction of IgG with $\mathrm{T}$ cells, or modulation of other cellular or molecular targets, particularly APCs such as DC and macrophages. IVIg can also interact with other cells, such as B cells or NK cells. In addition, IVIg can modulate the production of proinflammatory cytokines, which may play a role in maintaining T-cell tolerance.

\section{The Effect of IVIg on DC Activation}

Induction of protective $\mathrm{T}$-cell responses requires naive $\mathrm{T}$ cells to receive signals via the TCR, costimulatory molecules, and cytokine receptors. These signals, via cell-cell contact and through soluble mediators, are provided by professional APCs, such as DC. While DC represent the most efficient APC in capturing, processing, and presenting antigens to $\mathrm{T}$ cells (55), DC also play an active role in maintaining immune tolerance, as constitutive DC ablation results in spontaneous fatal autoimmunity (56). Tolerogenic DCs are characterized by decreased expression of costimulatory molecules (CD40, CD80, and CD86), decreased antigen presentation (due to reduced MHC class II expression), enhanced expression of coinhibitory molecules (e.g., PD-L1, CTLA-4, and OX-40), and enhanced inhibitory cytokine production $(57,58)$. This DC subset is essential for maintaining tolerance via extrathymic induction of $\mathrm{p}$ Treg and maintenance of pre-existing tTreg (59-62).

Induction of tolerance is critically dependent on the maturation state of DC. An immature DC phenotype is associated with induction, expansion, or enhancement of the suppressive capacity of Treg (63). Direct cell-to-cell interaction of DC and T cells via TCR (64), induction of indolamine-2,3-dioxygenase (IDO) (65), as well as secretion of IL-10, TGF- $\beta$, and retinoic acid by DC (66) are all implicated in the peripheral induction or expansion of Treg by DC.

Although both myeloid and plasmacytoid DC may be involved in maintaining peripheral tolerance (67), polyclonal human IgG appears to target $\mathrm{CD} 11 \mathrm{c}^{+} \mathrm{DC}$ rather than $\mathrm{CD} 11 \mathrm{c}^{-}$plasmacytoid DC $(49,68)$. We have demonstrated that CD11 $c^{+}$DC from IVIgtreated mice are necessary and sufficient for peripheral induction of Treg in lung and draining thoracic lymph nodes (49). IVIg decreases CD80 and CD86 both in vitro and in vivo; in addition, adoptively transferred IVIg-treated DC can increase Treg in lungs of antigen-exposed and challenged mice $(49,69)$.

Intravenous immunoglobulin-exposed CD11 $\mathrm{c}^{+} \mathrm{DCs}$ are less competent in driving lymphocyte proliferation, potentially due to decreased MHC-II and CD80/CD86 expression (68,70-72). Work from the group of Bazin suggests that internalized IVIg interferes with antigen presentation by competing with antigen peptides for loading on MHC-II molecules in the intracellular MHC-II compartment (MIIC) $(73,74)$. Inhibition of T-cell responses by reducing antigen presentation may also interfere with the activation of autoreactive pathogenic T cells. In addition, IVIg alters the pattern of DC cytokine production, including up-regulation of inhibitory cytokines, such as IL-10, and down-regulation of proinflammatory cytokines, such as IL-12 and IFN- $\gamma(53,71,75)$.
Proinflammatory cytokines counteract Treg differentiation or decrease Treg suppressive effects. For example, IL-6 secretion from DC is known to abrogate Treg anergy, reverse Treg suppression, and skew Treg differentiation toward Th-17 $(76,77)$. In contrast, IVIg reduces the production of IL- 6 and TNF- $\alpha$ by peripheral blood monocytes $(78,79)$; it can therefore maintain Treg homeostasis. It is conceivable that IVIg-generated Treg may attenuate DC maturation by anti-inflammatory cytokine production, expanding the inhibitory effects of IVIg by further tolerizing DC in a negative feedback loop.

How IVIg targets DC is still incompletely elucidated, and different mechanisms have been postulated. The effect of polyclonal IgG on DC appears to involve activating Fc $\gamma \mathrm{R}$, by triggering immunoreceptor tyrosine-based activation motifs (ITAM) (80). However, both $\mathrm{Fc}$ and $\mathrm{F}\left(\mathrm{ab}^{\prime}\right)^{2}$ fragments of IgG have been shown to suppress DC maturation and modulate DC cytokine production (71). $\mathrm{F}\left(\mathrm{ab}^{\prime}\right)^{2}$ fragments have been shown to inhibit LPS-induced phosphorylation of extracellular signal-regulated kinase (ERK1/2), an intracellular signaling molecule that mediates the inflammatory response induced by Toll-like receptor (TLR) ligation in DC (81).

Although a full discussion of IVIg-Fcy receptor biology is beyond the scope of this review, it is important to note that inhibitory Fc $\gamma$ RIIB were required for the anti-inflammatory effects of IVIg in murine models of ITP (72), nephrotoxic nephritis (82), and epidermolysis bullosa acquisita (EBA) (54). Similarly, we have found that FcyRIIB is required for IVIg-mediated abrogation of allergic airways disease (Kaufman et al., in preparation). Up-regulation of Fc $\gamma$ RIIB expression on DC, and on APC in general, likely plays a role in the suppression of DC activation, although no direct physical interaction between IVIg with this receptor has been reported (83).

De Groot et al. (84) proposed another DC-dependent mechanism by which IVIg promotes Treg expansion. They described promiscuous IgG-derived T-cell epitope peptides (Tregitopes) containing epitopes from both Fc and Fab fragments of the IgG molecule, with the capability of activating Foxp $3^{+}$Treg. They postulated that these Tregitopes are presented in the context of MHC-II by APC to Treg and contribute to Treg activation and expansion $(85,86)$. This is consistent with the results of Franco et al. (36) discussed earlier where B cells presented Fc regions of IgG in a MHC-restricted and TCR-mediated manner.

\section{The Anti-Inflammatory Effects of Sialylated IgG and its Relationship to Treg Development}

Human IgG therapy has two consistently used dosing regimens. Patients requiring immune supplementation for immune deficiency typically receive between 400 and $800 \mathrm{mg} / \mathrm{kg}$ monthly. After many years of using lower doses, these were deemed ineffective in crossover studies. Individuals requiring immune modulation frequently receive infusion of IVIg containing two to five times the immune supplementation dose. It has therefore been hypothesized that minor fractions of IVIg provide molecules that supply the anti-inflammatory components needed for immune modulation. This has been demonstrated regarding specific neutralizing antibodies, anti-idiotypic antibodies, or anti-apoptosis antibodies. 
The Ravetch group developed the concept that the antiinflammatory properties of IVIg were isolated to an IgG subset characterized by terminal $\alpha-2,6$-sialylation of the Fc glycan. Specifically, the Fc portion of the IgG molecule contained an N-linked glycan moiety covalently bound to a highly conserved glycosylation site at Asn297 $(87,88)$. In various clinical scenarios, lower serum levels of sialylated IgG were found in individuals with systemic lupus erythematosus or juvenile-onset rheumatoid arthritis when compared with healthy controls (89-91). This sialylated fraction of IVIg (saIVIg) makes up roughly $1-2 \%$ of the total IgG in pooled therapeutic preparations. In proof-of-concept studies, saIVIg was therapeutically effective in animal models of rheumatoid arthritis (92), ITP (93), and allergic airways disease (94) at doses 10 times lower than unfractionated IVIg.

The mechanism of action of saIVIg is still under investigation. Kaneko et al. (87) proposed that saIVIg interacts with DC-SIGN (DC-specific intercellular adhesion molecule-3 grabbing non-integrin) on human DC or the murine ortholog SIGN-R1 (specific intracellular adhesion molecule-3 grabbing nonintegrin homolog-related 1) on murine splenic macrophages. This triggers increased expression of the inhibitory $\mathrm{Fc}$ receptor Fc $\gamma$ RIIB (88). This may contribute to the induction and expansion of Treg; Fc $\gamma$ RIIB-deficient mice are incapable of generating Treg in a model of mucosal antigen tolerance (95). Guilliams et al. reviewed the role of Fc $\gamma$ RIIB in IVIg therapy and suggested that IVIg increases FcyRIIB expression in inflamed tissues during the effector phase of the immune response (96).

Using experimental models of multiple sclerosis (EAE) and serum-induced arthritis, Fiebiger et al. (97) recently reported that saIVIg Fc confers protective effects in T-cell-mediated and antibody-mediated diseases. They developed a mutated IgG Fc construct (F241A), which had a similar structure to saIVIg Fc, but displayed DC-SIGN binding independent of sialylation. Both saIVIg Fc and F241A IgG Fc alleviated arthritis and EAE by inducing Treg expansion and activation, up-regulating Fc $\gamma$ RIIB on effector macrophages, and suppressing Th17 and Th1 responses. The anti-inflammatory responses required expression of DC-SIGN as well as secretion of IL-33 by macrophages.

Washburn et al. described a novel hypersialylated IgG derivative, tetra-Fc-sialylated IVIg (s4-IVIg), which was maximally sialylated but lacked advanced glycation end products (AGEs) that are hazardous to human health. s4-IVIg was efficacious in animal models of arthritis, ITP, and EBA (91). These results substantiate data obtained by Schwab et al. (54) who demonstrated requirements for IgG sialylation and Fc $\gamma$ RIIB expression in their disease models.

As IVIg is a heterogeneous compound, it is not surprising that non-sialylated IgG is also biologically active. Othy et al. demonstrated the effects of IVIg on Th17 and Treg cells independent of Fc sialylation (98). Similarly, there are studies using different murine models of ITP $(99,100)$ and rheumatoid arthritis (101), which did not require sialylated IgG. Differences in strains or induction of pathological conditions in various murine models are reasons for the discrepancies in the dependence on sialylation. To obtain more definitive results, it will be critical to evaluate the role of minor IgG fractions in subjects with inflammatory and autoimmune diseases.

\section{IVIg Binds C-Type Lectin Receptors on DCs}

DC-specific intercellular adhesion molecule-3 grabbing nonintegrin and SIGN-R1 are C-type lectin receptors, which bind mannosylated and fucosylated structures, such as HIV envelope protein gp120 (102). While ligation of DC-SIGN by mannoseexpressing pathogens stimulates proinflammatory cytokine secretion by DC, fucose-expressing pathogens or synthetic fucose-containing ligands inhibit LPS-induced production of IL- 6 and IL-12 and stimulate the secretion of anti-inflammatory IL-10 by DC (103). Hence, ligation of these innate receptors by saIVIg may regulate cytokine production by DC and therefore contribute to Treg homeostasis. Smits et al. (104) showed that binding of Lactobacillus reuteri and Lactobacillus casei bacteria to DC-SIGN on monocyte-derived DC drove the development of Treg. These Treg produced increased levels of IL-10 and were capable of inhibiting the proliferation of bystander $\mathrm{T}$ cells in an IL-10-dependent fashion.

Work from the group of Ravetch and other investigators suggests that the conformational changes in IgG molecules induced by sialylation lead to a reduction in binding affinity of IgG to Fc $\gamma \mathrm{R}$ by masking the $\mathrm{Fc} \gamma \mathrm{R}$ binding site (105). Furthermore, sialylation exposes a binding site on IgG for carbohydrate-binding C-type lectin receptors such as DC-SIGN or SIGN-R1 $(89,97,106)$. In contrast, the group of Crispin were unable to reproduce these findings, claiming that sialylation of IgG does not result in conformational changes to the $\operatorname{IgG}$ molecule or increases in binding affinity of IgG to DC-SIGN $(107,108)$. They suggest that crosslinking of sialic-acid-binding Siglecs (sialic acid binding Ig-like lectins), such as CD22, and direct binding of Fc receptors induce inhibitory signaling through immunoreceptor tyrosine-based inhibition motif (ITIM) pathways. We have recently described that IVIg efficiently modifies DCs to induce regulatory $\mathrm{T}$ cells in the absence of activating Fc $\gamma \mathrm{R}$ (94). It is worth noting that the sialylation of IgG is not restricted to the Fc fragment, and a high proportion of sialic acid residues on the $F\left(\mathrm{ab}^{\prime}\right)^{2}$ fragments of IgG has been identified recently by Kasemann et al. (109).

In addition to DC-SIGN, other C-type lectin receptors may interact with IVIg and contribute to induction and/or expansion of Treg. We have recently reported (94) that saIVIg specifically interacts with the C-type lectin dendritic cell immunoreceptor (DCIR)

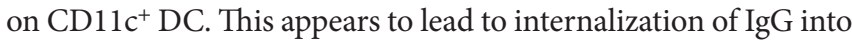
$\mathrm{DC}$ and is associated with inhibitory signaling in ligated DC that consequently results in the peripheral induction of Foxp $3^{+}$Treg. The contribution of $\mathrm{DCIR}^{+} \mathrm{DC}$ in the induction and expansion of Treg has been demonstrated in previous studies, although not in the context of IVIg therapy. Yamazaki et al. (110) showed that two subsets of $\mathrm{CD}^{+} \mathrm{CD} 205^{+}$and $\mathrm{CD} 8^{-} \mathrm{DCIR}^{+} \mathrm{DC}$ differentiate peripheral Foxp $3^{+}$Treg, in part through the endogenous production of TGF- $\beta$. These data indicate that multiple C-lectin receptors are implicated in the generation of tolerogenic DC by IVIg.

\section{Interaction of IVIg with Treg}

Direct interaction of polyclonal IgG with Treg may represent another mechanism by which IVIg can induce tolerance. Kessel et al. (29) demonstrated that IVIg increases expression of intracellular FOXP3, TGF- $\beta$, and IL-10 when added to culture with human $\mathrm{CD}^{+} \mathrm{T}$ cells. IgG was shown to bind to both human 
and mouse Treg $(39,111)$, which increased FOXP3 expression, accompanied by augmented ex vivo suppressive function. IVIg stimulated phosphorylation of ZAP-70 in Treg (111), which is known to enhance suppressive activity (112).

Additionally, interaction of IgG with effector T cells can affect the balance of cytokine production, mainly by downregulating proinflammatory cytokines, such as IL-2, IFN- $\gamma$, and TNF- $\alpha$, and increasing inhibitory cytokines $(113,114)$. Early work (115) on cytokine networks elucidated that IVIg abrogated production of both Th1- and Th2-type proinflammatory cytokines from PBMC in culture. Maddur et al. (116) demonstrated the reciprocal enhancement of Treg differentiation compared to inhibition of Th17 differentiation in culture, in association with decreases in Th17 effector cytokines (IL-17A, IL-17F, IL-21, and CCL20). In clinical trials, two groups have investigated the effect of IVIg therapy on the profile of intracellular cytokine expression in T cells. In ITP patients who were responsive to IVIg therapy, there was increased production of IL-10 and TGF- $\beta$ by CD $4^{+} \mathrm{T}$ cells as well as decreased Th-1 cytokine production $(117,118)$.

Experiments from our laboratory could not confirm direct action of IVIg on T cells on the induction of Treg. We examined naive $\mathrm{CD}^{+}{ }^{+}$Foxp $3^{-} \mathrm{T}$ cells from Foxp3-GFP reporter mice in the absence of APC. Pre-treatment of these cells with IVIg, followed by coculture with DC and a source of antigen, did not result in the induction of Foxp3 expression, whereas IVIg pretreatment of DC prior to coculture induced Treg ex vivo. Further, we found that (49), in allergic airways disease, Treg induction required CD $11 c^{+}$ DC both in vitro and in vivo, suggesting that the DC compartment is the main target of IVIg in our system. We therefore hypothesize that IVIg first tolerizes DC, which in turn induce Treg.

Modification of chemokine or chemokine receptors on circulating leukocytes is another potential mode of action of IVIg, which would lead to recruitment of cells to specific tissue sites. Evidence suggests that Treg compartmentalization and trafficking are tissue- or organ-specific and that distinct chemokine receptor and integrin expression may contribute to selective trafficking of Treg to inflammatory microenvironments (119). For instance, expression of chemokine receptors CCR 4 and CCR8 are required on Treg for tissue homing (120). Treg may switch their homing receptor expression profiles depending on the direction of their trafficking. A majority of Treg found in secondary lymphoid tissues express CD62L and CCR7 (121). Moreover, while both effector and regulatory $\mathrm{T}$ cells might express similar patterns of chemokine receptors, both subsets may compete for interaction with APC or access to the site of inflammation.

We have demonstrated in a mouse model of ovalbumindriven allergic airway disease that IVIg specifically increases the expression of CCR4 on the induced Treg population, suggesting their enhanced ability to recruit to the site of inflammation. Additionally, we found that expression of CD62L, which acts as a homing receptor for lymphocytes entering secondary lymphoid tissues, is decreased in Treg isolated from inflamed lung tissues (49). In a murine model of ITP, Treg compartmentalization was also modified by IVIg therapy (50), stressing the potential for action of IVIg on chemokine receptor expression. It is unclear if this action is direct or indirect, via signals from APC.

\section{Conclusion}

Intravenous immunoglobulin is an extremely complex preparation that contains a multitude of biologically active moieties: it likely achieves immunomodulation through a number of synergistic mechanisms, which provide positive therapeutic effects. The immune-regulatory effects of IVIg appear to be pleiotropic and involve different stages of the inflammatory cascade, with a complex interplay of IgG molecules with different cells and mediators.

In this review, we describe potential mechanisms behind the actions of IVIg in the generation and differentiation of Treg. Recent findings reinforce the efficacy of IVIg in the enhancement of Treg in various autoimmune disorders. The action of IVIg in the modulation of Treg, and the consequent maintenance of immune tolerance, provides a rationale for therapeutic approaches specifically targeting this axis of the immune system. This also renews interest in developing alternative treatments, such as Tregitopes or monoclonal antibodies, for refractory inflammatory and autoimmune diseases, which are often associated with deficiencies in Treg and are difficult to manage with conventional therapeutic approaches.

The effects of IVIg on the potentiation of Treg appear to involve the interaction of IgG with APC and potentially T cells and are dependent on the modulation of cytokine networks within different immune cell types. Based on our own studies and the conclusions of this review, we suggest a set of potential cellular mechanisms, which are summarized schematically in Figure 1. Initially, saIVIg binds C-type lectin receptors on DCs (Figure 1A), which induces inhibitory FcyRIIB expression on DC or on effector macrophages (Figure 1B), thus potentiating the activation threshold of the adaptive arm of the immune system. The associated inhibitory receptor signaling renders the DC tolerogenic, reducing DC costimulatory molecule expression (Figure 1C) and proinflammatory cytokine secretion (Figure 1D). Anti-inflammatory cytokine and mediator production by both DC and Treg (Figure 1E) and presentation of IgG regulatory epitopes (Figure 1F) to Treg by DC decrease proinflammatory cytokine production in naive effector T cells (Figure 1G) and generate Treg from non-Treg precursors (Figure 1H). These Treg inhibit effector Th1, Th2, and Th17 cell proliferation and activity (Figure 1I) in the inflammatory microenvironment and secrete anti-inflammatory cytokines (Figure 1E) that tolerize DC. In addition, IVIg-mediated modulation of chemokine or chemokine receptor expression in T-cell subsets might contribute to the homeostasis or regulation of trafficking of Treg, although proper functional characterization is needed. NK cells play a role in processing of innate antigens and have multiple known ITIMlinked receptors: IVIg may target NK cells to directly induce Treg by cytokine production or cell-cell contact (discussed earlier). IVIg-treated NK cells may also induce antibody-dependent cellular cytotoxicity of mature DC, which reduces antigen presentation and inhibits proinflammatory effector T-cell function (122).

Interaction of sialylated IgG with C-type lectin receptors triggers an inhibitory response in ligated cells that might consequently provide the required signals for maintaining immune tolerance. In this review, we bring evidence that shows the association of this interaction with the promotion of Treg. However, more investigation is still required to elucidate the 


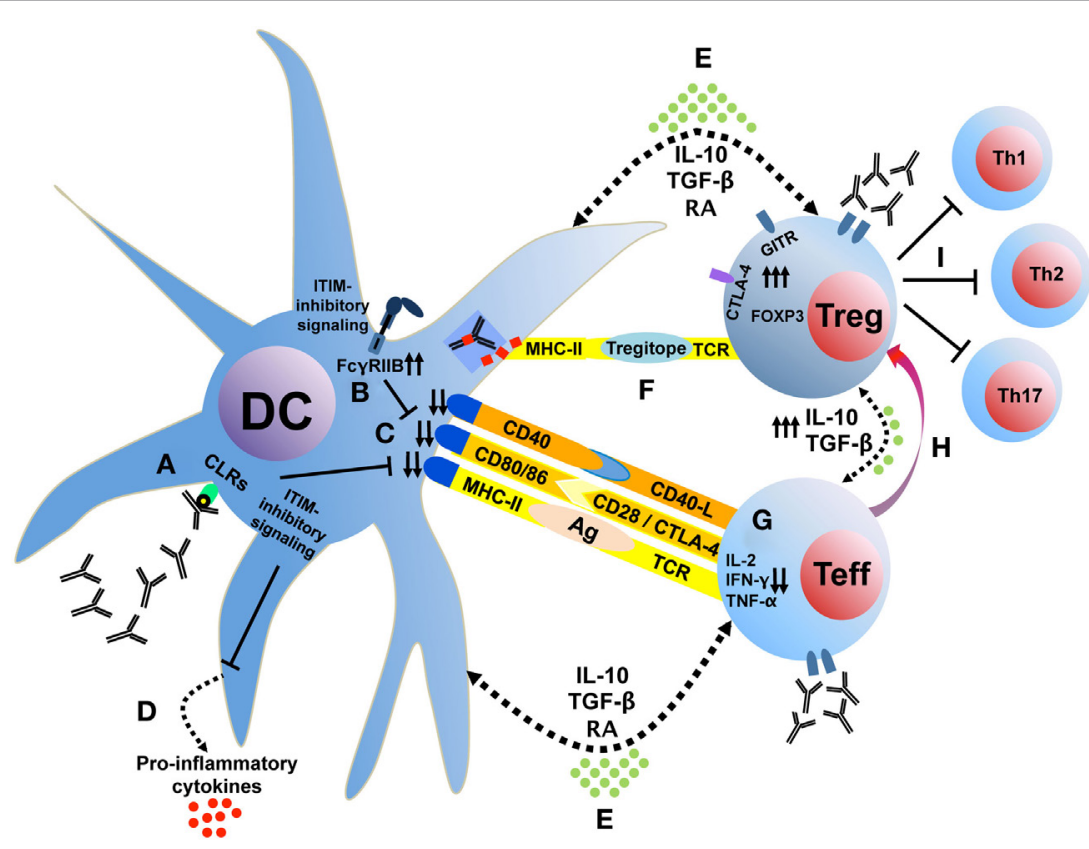

FIGURE 1 | IVIg tolerizes DC, which interacts with T cells to induce Treg. Sialylated IVlg ligates C-type lectin receptors on DC (A), which induces Fc $\gamma$ RIIB expression (B) and reduces costimulatory molecule expression (C) and proinflammatory cytokine secretion (D). Anti-inflammatory cytokine and mediator production (E) and presentation of IgG regulatory epitopes (F) decrease proinflammatory cytokine production in naive effector T cells (G) and generate Treg from non-Treg precursors (H). These Treg inhibit effector Th1, Th2, and Th17 cell proliferation and activity (I) in the inflammatory microenvironment and secrete anti-inflammatory cytokines (E) that tolerize DC. CLRs, C-type lectin receptors; GITR, glucocorticoid-induced TNFR family related gene; ITIM, immunoreceptor tyrosine-based inhibition motif; $R A$, retinoic acid.

beneficial effects of IVIg in modulation of Treg, particularly in clinical trials. Further avenues of research include identifying specific cellular markers or phenotypic patterns associated with DC tolerogenicity as well as precise characterization of the IVIggenerated Treg population.

\section{Author Contributions}

GK, AM, MD, and MY surveyed the literature and wrote the article. GK, CP, and BM revised the article. All authors approved the final version of this article for publication and accept responsibility for the integrity of the work.

\section{References}

1. Bruton OC. Agammaglobulinemia. Pediatrics (1952) 9(6):722-8.

2. Imbach $\mathrm{P}$, Barandun S, Baumgartner C, Hirt A, Hofer F, Wagner HP. High-dose intravenous gammaglobulin therapy of refractory, in particular idiopathic thrombocytopenia in childhood. Helv Paediatr Acta (1981) 36(1):81-6.

3. Nimmerjahn F, Ravetch JV. Anti-inflammatory actions of intravenous immunoglobulin. Annu Rev Immunol (2008) 26:513-33. doi:10.1146/annurev. immunol.26.021607.090232

4. Group IC, Brocklehurst P, Farrell B, King A, Juszczak E, Darlow B, et al. Treatment of neonatal sepsis with intravenous immune globulin. $N$ Engl $J$ Med (2011) 365(13):1201-11. doi:10.1056/NEJMoa1100441

5. Ohlsson A, Lacy JB. Intravenous immunoglobulin for preventing infection in preterm and/or low birth weight infants. Cochrane Database Syst Rev (2013) 7:CD000361. doi:10.1002/14651858.CD000361.pub3

\section{Acknowledgments}

We acknowledge the financial support of Talecris and Grifols Bioscience (Clinical Investigation Program), Canadian Institutes for Health Research [CIHR grants ISO115295 (BM) and MOP67211 (CP)], The Research Institute of the McGill University Health Centre (RI-MUHC), the Fonds de recherche du Québec - Santé (FRQS) and the Strauss Family Foundation. We thank Marylin Desjardins, MD, for her expert advice and critical comments. GK is the recipient of a CIHR Canada Graduate Scholarships Doctoral Research Award. CP holds a CIHR Canada Research Chair.

6. Ohlsson A, Lacy JB. Intravenous immunoglobulin for suspected or proven infection in neonates. Cochrane Database Syst Rev (2013) 7:CD001239. doi:10.1002/14651858.CD001239.pub4

7. Akdag A, Dilmen U, Haque K, Dilli D, Erdeve O, Goekmen T. Role of pentoxifylline and/or IgM-enriched intravenous immunoglobulin in the management of neonatal sepsis. Am J Perinatol (2014) 31(10):905-12. doi:10 .1055/s-0033-1363771

8. Capasso L, Borrelli AC, Parrella C, Lama S, Ferrara T, Coppola C, et al. Are IgM-enriched immunoglobulins an effective adjuvant in septic VLBW infants? Ital J Pediatr (2013) 39:63. doi:10.1186/1824-7288-39-63

9. Kazatchkine MD, Kaveri SV. Immunomodulation of autoimmune and inflammatory diseases with intravenous immune globulin. $N$ Engl J Med (2001) 345(10):747-55. doi:10.1056/NEJMra993360

10. Gold R, Stangel M, Dalakas MC. Drug Insight: the use of intravenous immunoglobulin in neurology - therapeutic considerations and practical issues. Nat Clin Pract Neurol (2007) 3(1):36-44. doi:10.1038/ncpneuro0376 
11. Sakaguchi S, Sakaguchi N, Asano M, Itoh M, Toda M. Immunologic self-tolerance maintained by activated $\mathrm{T}$ cells expressing IL- 2 receptor alpha-chains (CD25). Breakdown of a single mechanism of self-tolerance causes various autoimmune diseases. J Immunol (1995) 155(3):1151-64.

12. Tang Q, Bluestone JA. The Foxp3+ regulatory $\mathrm{T}$ cell: a jack of all trades, master of regulation. Nat Immunol (2008) 9(3):239-44. doi:10.1038/ni1572

13. Piccirillo CA, Shevach EM. Naturally-occurring CD4+CD25+ immunoregulatory T cells: central players in the arena of peripheral tolerance. Semin Immunol (2004) 16(2):81-8. doi:10.1016/j.smim.2003.12.003

14. Hori S, Nomura T, Sakaguchi S. Control of regulatory T cell development by the transcription factor Foxp3. Science (2003) 299(5609):1057-61. doi:10.1126/science. 1079490

15. Vigouroux S, Yvon E, Biagi E, Brenner MK. Antigen-induced regulatory T cells. Blood (2004) 104(1):26-33. doi:10.1182/blood-2004-01-0182

16. d'Hennezel E, Yurchenko E, Sgouroudis E, Hay V, Piccirillo CA. Singlecell analysis of the human $\mathrm{T}$ regulatory population uncovers functional heterogeneity and instability within FOXP3+ cells. J Immunol (2011) 186(12):6788-97. doi:10.4049/jimmunol.1100269

17. Bin Dhuban K, Kornete M, Mason SE, Piccirillo CA. Functional dynamics of Foxp3(+) regulatory T cells in mice and humans. Immunol Rev (2014) 259(1):140-58. doi:10.1111/imr.12168

18. Bin Dhuban K, d'Hennezel E, Nashi E, Bar-Or A, Rieder S, Shevach EM, et al. Coexpression of TIGIT and FCRL3 identifies Helios+ human memory regulatory $\mathrm{T}$ cells. J Immunol (2015) 194(8):3687-96. doi:10.4049/ jimmunol.1401803

19. Pilat N, Baranyi U, Klaus C, Jaeckel E, Mpofu N, Wrba F, et al. Tregtherapy allows mixed chimerism and transplantation tolerance without cytoreductive conditioning. Am J Transplant (2010) 10(4):751-62. doi:10.1111/j.1600-6143.2010.03018.x

20. Xu W, Lan Q, Chen M, Chen H, Zhu N, Zhou X, et al. Adoptive transfer of induced-Treg cells effectively attenuates murine airway allergic inflammation. PLoS One (2012) 7(7):e40314. doi:10.1371/journal. pone.0040314

21. Riley JL, June $\mathrm{CH}$, Blazar BR. Human $\mathrm{T}$ regulatory cell therapy: take a billion or so and call me in the morning. Immunity (2009) 30(5):656-65. doi:10.1016/j.immuni.2009.04.006

22. Battaglia M, Stabilini A, Roncarolo MG. Rapamycin selectively expands CD4+CD25+FoxP3+ regulatory T cells. Blood (2005) 105(12):4743-8. doi:10.1182/blood-2004-10-3932

23. Ray A, Khare A, Krishnamoorthy N, Qi Z, Ray P. Regulatory T cells in many flavors control asthma. Mucosal Immunol (2010) 3(3):216-29. doi:10.1038/ mi.2010.4

24. Bayry J, Mouthon L, Kaveri SV. Intravenous immunoglobulin expands regulatory $\mathrm{T}$ cells in autoimmune rheumatic disease. J Rheumatol (2012) 39(2):450-1. doi:10.3899/jrheum.111123

25. Durandy A, Fischer A, Griscelli C. Dysfunctions of pokeweed mitogen-stimulated $\mathrm{T}$ and $\mathrm{B}$ lymphocyte responses induced by gammaglobulin therapy. J Clin Invest (1981) 67(3):867-77. doi:10.1172/JCI110104

26. Sany J, Clot J, Bonneau M, Andary M. Immunomodulating effect of human placenta-eluted gamma globulins in rheumatoid arthritis. Arthritis Rheum (1982) 25(1):17-24. doi:10.1002/art.1780250103

27. Delfraissy JF, Tchernia G, Laurian Y, Wallon C, Galanaud P, Dormont J. Suppressor cell function after intravenous gammaglobulin treatment in adult chronic idiopathic thrombocytopenic purpura. Br J Haematol (1985) 60(2):315-22. doi:10.1111/j.1365-2141.1985.tb07417.x

28. Gupta A, Novick BE, Rubinstein A. Restoration of suppressor T-cell functions in children with AIDS following intravenous gamma globulin treatment. Am J Dis Child (1986) 140(2):143-6.

29. Kessel A, Ammuri H, Peri R, Pavlotzky ER, Blank M, Shoenfeld Y, et al. Intravenous immunoglobulin therapy affects $\mathrm{T}$ regulatory cells by increasing their suppressive function. J Immunol (2007) 179(8):5571-5. doi:10.4049/ jimmunol.179.8.5571

30. Chi LJ, Wang HB, Zhang Y, Wang WZ. Abnormality of circulating CD4(+)CD25(+) regulatory $\mathrm{T}$ cell in patients with Guillain-Barre syndrome. J Neuroimmunol (2007) 192(1-2):206-14. doi:10.1016/j. jneuroim.2007.09.034

31. Barreto M, Ferreira RC, Lourenco L, Moraes-Fontes MF, Santos E, Alves M, et al. Low frequency of CD4+CD25+ Treg in SLE patients: a heritable trait associated with CTLA4 and TGFbeta gene variants. BMC Immunol (2009) 10:5. doi:10.1186/1471-2172-10-5

32. Tsurikisawa N, Saito H, Oshikata C, Tsuburai T, Akiyama K. High-dose intravenous immunoglobulin treatment increases regulatory $\mathrm{T}$ cells in patients with eosinophilic granulomatosis with polyangiitis. J Rheumatol (2012) 39(5):1019-25. doi:10.3899/jrheum.110981

33. Tsurikisawa N, Taniguchi M, Saito H, Himeno H, Ishibashi A, Suzuki S, et al. Treatment of Churg-Strauss syndrome with high-dose intravenous immunoglobulin. Ann Allergy Asthma Immunol (2004) 92(1):80-7. doi:10.1016/ S1081-1206(10)61714-0

34. Burns JC, Glodé MP. Kawasaki syndrome. Lancet (2004) 364(9433):533-44. doi:10.1016/S0140-6736(04)16814-1

35. Burns JC, Song Y, Bujold M, Shimizu C, Kanegaye JT, Tremoulet AH, et al. Immune-monitoring in Kawasaki disease patients treated with infliximab and intravenous immunoglobulin. Clin Exp Immunol (2013) 174(3):337-44. doi:10.1111/cei.12182

36. Franco A, Touma R, Song Y, Shimizu C, Tremoulet AH, Kanegaye JT, et al. Specificity of regulatory $\mathrm{T}$ cells that modulate vascular inflammation. Autoimmunity (2014) 47(2):95-104. doi:10.3109/08916934.2 013.860524

37. Burns JC, Touma R, Song Y, Padilla RL, Tremoulet AH, Sidney J, et al. Fine specificities of natural regulatory T cells after IVIG therapy in patients with Kawasaki disease. Autoimmunity (2015) 48(3):181-8. doi:10.3109/08916934 .2015 .1027817

38. Anthony RM, Ravetch JV. A novel role for the IgG Fc glycan: the anti-inflammatory activity of sialylated IgG Fcs. J Clin Immunol (2010) 30(Suppl 1):S9-14. doi:10.1007/s10875-010-9405-6

39. Ephrem A, Chamat S, Miquel C, Fisson S, Mouthon L, Caligiuri G, et al. Expansion of CD4+CD25+ regulatory $\mathrm{T}$ cells by intravenous immunoglobulin: a critical factor in controlling experimental autoimmune encephalomyelitis. Blood (2008) 111(2):715-22. doi:10.1182/ blood-2007-03-079947

40. Ni FF, Li CR, Li Q, Xia Y, Wang GB, Yang J. Regulatory T cell microRNA expression changes in children with acute Kawasaki disease. Clin Exp Immunol (2014) 178(2):384-93. doi:10.1111/cei.12418

41. Okuda S, Kamei S, Harano S, Shinya N, Hayashida K, Sasaki T. [Enhancement of regulatory $\mathrm{T}$ cell induction by intravenous S-sulfonated Immunoglobulin during the treatment of experimental autoimmune encephalomyelitis]. Yakugaku Zasshi (2012) 132(2):243-9. doi:10.1248/yakushi.132.243

42. Bao Y, Han Y, Chen Z, Xu S, Cao X. IFN-alpha-producing PDCA-1+ Siglec-H- B cells mediate innate immune defense by activating NK cells. Eur J Immunol (2011) 41(3):657-68. doi:10.1002/eji.201040840

43. Bergmann C, Wild CA, Narwan M, Lotfi R, Lang S, Brandau S. Human tumor-induced and naturally occurring Treg cells differentially affect NK cells activated by either IL-2 or target cells. Eur J Immunol (2011) 41(12):3564-73. doi:10.1002/eji.201141532

44. Chong WP, Ling MT, Liu Y, Caspi RR, Wong WM, Wu W, et al. Essential role of NK cells in IgG therapy for experimental autoimmune encephalomyelitis. PLoS One (2013) 8(4):e60862. doi:10.1371/journal.pone.0060862

45. Moretta A. Natural killer cells and dendritic cells: rendezvous in abused tissues. Nat Rev Immunol (2002) 2(12):957-65. doi:10.1038/nri956

46. Zingoni A, Sornasse T, Cocks BG, Tanaka Y, Santoni A, Lanier LL. Crosstalk between activated human NK cells and CD4+ T cells via OX40-OX40 ligand interactions. J Immunol (2004) 173(6):3716-24. doi:10.4049/ jimmunol.173.6.3716

47. Liang S, Alard P, Zhao Y, Parnell S, Clark SL, Kosiewicz MM. Conversion of CD4+ CD25- cells into CD4+ CD25+ regulatory T cells in vivo requires B7 costimulation, but not the thymus. J Exp Med (2005) 201(1):127-37. doi:10.1084/jem.20041201

48. Griseri T, Asquith M, Thompson C, Powrie F. OX40 is required for regulatory T cell-mediated control of colitis. J Exp Med (2010) 207(4):699-709. doi:10.1084/jem.20091618

49. Massoud AH, Guay J, Shalaby KH, Bjur E, Ablona A, Chan D, et al. Intravenous immunoglobulin attenuates airway inflammation through induction of forkhead box protein 3-positive regulatory T cells. J Allergy Clin Immunol (2012) 129(6):1656-65. doi:10.1016/j.jaci.2012.02.050

50. Aslam R, Hu Y, Gebremeskel S, Segel GB, Speck ER, Guo L, et al. Thymic retention of $\mathrm{CD} 4+\mathrm{CD} 25+\mathrm{FoxP} 3+\mathrm{T}$ regulatory cells is associated with their peripheral deficiency and thrombocytopenia in a murine model of 
immune thrombocytopenia. Blood (2012) 120(10):2127-32. doi:10.1182/ blood-2012-02-413526

51. Kerr J, Quinti I, Eibl M, Chapel H, Spaeth PJ, Sewell WC, et al. Is dosing of therapeutic immunoglobulins optimal? - A review of a 3-decade long debate in Europe. Front Immunol (2014) 5:629. doi:10.3389/fimmu.2014.00629

52. Roifman CM, Levison H, Gelfand EW. High-dose versus low-dose intravenous immunoglobulin in hypogammaglobulinaemia and chronic lung disease. Lancet (1987) 1(8541):1075-7. doi:10.1016/S0140-6736(87)90494-6

53. Ramakrishna C, Newo AN, Shen YW, Cantin E. Passively administered pooled human immunoglobulins exert IL-10 dependent anti-inflammatory effects that protect against fatal HSV encephalitis. PLoS Pathog (2011) 7(6):e1002071. doi:10.1371/journal.ppat.1002071

54. Schwab I, Mihai S, Seeling M, Kasperkiewicz M, Ludwig RJ, Nimmerjahn F. Broad requirement for terminal sialic acid residues and FcgammaRIIB for the preventive and therapeutic activity of intravenous immunoglobulins in vivo. Eur J Immunol (2014) 44(5):1444-53. doi:10.1002/eji.201344230

55. Cines DB, Blanchette VS. Immune thrombocytopenic purpura. N Engl J Med (2002) 346(13):995-1008. doi:10.1056/NEJMra010501

56. Ohnmacht C, Pullner A, King SB, Drexler I, Meier S, Brocker T, et al. Constitutive ablation of dendritic cells breaks self-tolerance of CD4 T cells and results in spontaneous fatal autoimmunity. J Exp Med (2009) 206(3):549-59. doi:10.1084/jem.20082394

57. Adorini L. Tolerogenic dendritic cells induced by vitamin $\mathrm{D}$ receptor ligands enhance regulatory T cells inhibiting autoimmune diabetes. Ann N Y Acad Sci (2003) 987:258-61. doi:10.1111/j.1749-6632.2003.tb06057.x

58. Steinman RM, Hawiger D, Nussenzweig MC. Tolerogenic dendritic cells. Annu Rev Immunol (2003) 21:685-711. doi:10.1146/annurev. immunol.21.120601.141040

59. Kushwah R, Hu J. Role of dendritic cells in the induction of regulatory $\mathrm{T}$ cells. Cell Biosci (2011) 1(1):20. doi:10.1186/2045-3701-1-20

60. Zou T, Caton AJ, Koretzky GA, Kambayashi T. Dendritic cells induce regulatory $\mathrm{T}$ cell proliferation through antigen-dependent and -independent interactions. J Immunol (2010) 185(5):2790-9. doi:10.4049/jimmunol.0903740

61. Sun Y, Brown NK, Ruddy MJ, Miller ML, Lee Y, Wang Y, et al. B and T lymphocyte attenuator tempers early infection immunity. J Immunol (2009) 183(3):1946-51. doi:10.4049/jimmunol.0801866

62. Brandl C, Ortler S, Herrmann T, Cardell S, Lutz MB, Wiendl H. B7-H1deficiency enhances the potential of tolerogenic dendritic cells by activating CD1d-restricted type II NKT cells. PLoS One (2010) 5(5):e10800. doi:10.1371/ journal.pone. 0010800

63. Kubo T, Hatton RD, Oliver J, Liu X, Elson CO, Weaver CT. Regulatory T cell suppression and anergy are differentially regulated by proinflammatory cytokines produced by TLR-activated dendritic cells. J Immunol (2004) 173(12):7249-58. doi:10.4049/jimmunol.173.12.7249

64. Bhattacharya P, Gopisetty A, Ganesh BB, Sheng JR, Prabhakar BS. GM-CSFinduced, bone-marrow-derived dendritic cells can expand natural Tregs and induce adaptive Tregs by different mechanisms. J Leukoc Biol (2011) 89(2):235-49. doi:10.1189/jlb.0310154

65. Loubaki L, Chabot D, Bazin R. Involvement of the TNF-alpha/TGF-beta/ IDO axis in IVIg-induced immune tolerance. Cytokine (2015) 71(2):181-7. doi:10.1016/j.cyto.2014.10.016

66. Maldonado RA, von Andrian UH. How tolerogenic dendritic cells induce regulatory T cells. Adv Immunol (2010) 108:111-65. doi:10.1016/ B978-0-12-380995-7.00004-5

67. Kuipers H, Lambrecht BN. The interplay of dendritic cells, Th2 cells and regulatory $\mathrm{T}$ cells in asthma. Curr Opin Immunol (2004) 16(6):702-8. doi:10.1016/j.coi.2004.09.010

68. Kaufman GN, Massoud AH, Audusseau S, Banville-Langelier AA, Wang $\mathrm{Y}$, Guay J, et al. Intravenous immunoglobulin attenuates airway hyperresponsiveness in a murine model of allergic asthma. Clin Exp Allergy (2011) 41(5):718-28. doi:10.1111/j.1365-2222.2010.03663.x

69. Yamamoto M, Kobayashi K, Ishikawa Y, Nakata K, Funada Y, Kotani Y, et al. The inhibitory effects of intravenous administration of rabbit immunoglobulin $\mathrm{G}$ on airway inflammation are dependent upon Fcgamma receptor IIb on CD11c(+) dendritic cells in a murine model. Clin Exp Immunol (2010) 162(2):315-24. doi:10.1111/j.1365-2249.2010.04243.x

70. Qian J, Zhu J, Wang M, Wu S, Chen T. Suppressive effects of intravenous immunoglobulin (IVIG) on human umbilical cord blood immune cells. Pediatr Allergy Immunol (2011) 22(2):211-20. doi:10.1111/j.1399-3038.2010.01049.x
71. Bayry J, Lacroix-Desmazes S, Carbonneil C, Misra N, Donkova V, Pashov $A$, et al. Inhibition of maturation and function of dendritic cells by intravenous immunoglobulin. Blood (2003) 101(2):758-65. doi:10.1182/ blood-2002-05-1447

72. Samuelsson A, Towers TL, Ravetch JV. Anti-inflammatory activity of IVIG mediated through the inhibitory Fc receptor. Science (2001) 291(5503):484-6. doi:10.1126/science.291.5503.484

73. Trepanier P, Aubin E, Bazin R. IVIg-mediated inhibition of antigen presentation: predominant role of naturally occurring cationic IgG. Clin Immunol (2012) 142(3):383-9. doi:10.1016/j.clim.2011.12.014

74. Aubin E, Lemieux R, Bazin R. Indirect inhibition of in vivo and in vitro T-cell responses by intravenous immunoglobulins due to impaired antigen presentation. Blood (2010) 115(9):1727-34. doi:10.1182/blood-2009-06-225417

75. Ohkuma K, Sasaki T, Kamei S, Okuda S, Nakano H, Hamamoto T, et al. Modulation of dendritic cell development by immunoglobulin $G$ in control subjects and multiple sclerosis patients. Clin Exp Immunol (2007) 150(3):397-406. doi:10.1111/j.1365-2249.2007.03496.x

76. Veldhoen M, Hocking RJ, Atkins CJ, Locksley RM, Stockinger B. TGFbeta in the context of an inflammatory cytokine milieu supports de novo differentiation of IL-17-producing T cells. Immunity (2006) 24(2):179-89. doi:10.1016/j.immuni.2006.01.001

77. Pasare C, Medzhitov R. Toll pathway-dependent blockade of CD4+CD25+ T cell-mediated suppression by dendritic cells. Science (2003) 299(5609):10336. doi:10.1126/science. 1078231

78. Andersson JP, Andersson UG. Human intravenous immunoglobulin modulates monokine production in vitro. Immunology (1990) 71(3):372-6.

79. Darville $\mathrm{T}$, Tabor $\mathrm{D}$, Simpson $\mathrm{K}$, Jacobs RF. Intravenous immunoglobulin modulates human mononuclear phagocyte tumor necrosis factor-alpha production in vitro. Pediatr Res (1994) 35(4 Pt 1):397-403. doi:10.1203/00006450-199404000-00004

80. Clynes R. IVIG therapy: interfering with interferon-gamma. Immunity (2007) 26(1):4-6. doi:10.1016/j.immuni.2007.01.006

81. Bayry J, Bansal K, Kazatchkine MD, Kaveri SV. DC-SIGN and alpha2,6-sialylated IgG Fc interaction is dispensable for the anti-inflammatory activity of IVIg on human dendritic cells. Proc Natl Acad Sci U S A (2009) 106(9):E24. author reply E5.

82. Kaneko Y, Nimmerjahn F, Madaio MP, Ravetch JV. Pathology and protection in nephrotoxic nephritis is determined by selective engagement of specific $\mathrm{Fc}$ receptors. J Exp Med (2006) 203(3):789-97. doi:10.1084/jem.20051900

83. Siragam V, Crow AR, Brinc D, Song S, Freedman J, Lazarus AH. Intravenous immunoglobulin ameliorates ITP via activating Fc gamma receptors on dendritic cells. Nat Med (2006) 12(6):688-92. doi:10.1038/nm1416

84. De Groot AS, Moise L, McMurry JA, Wambre E, Van Overtvelt L, Moingeon $\mathrm{P}$, et al. Activation of natural regulatory $\mathrm{T}$ cells by $\mathrm{IgG}$ Fc-derived peptide "Tregitopes". Blood (2008) 112(8):3303-11. doi:10.1182/ blood-2008-02-138073

85. Cousens LP, Najafian N, Mingozzi F, Elyaman W, Mazer B, Moise L, et al. In vitro and in vivo studies of IgG-derived Treg epitopes (Tregitopes): a promising new tool for tolerance induction and treatment of autoimmunity. J Clin Immunol (2013) 33(Suppl 1):S43-9. doi:10.1007/s10875-012-9762-4

86. Elyaman W, Khoury SJ, Scott DW, De Groot AS. Potential application of tregitopes as immunomodulating agents in multiple sclerosis. Neurol Res Int (2011) 2011:256460. doi:10.1155/2011/256460

87. Kaneko Y, Nimmerjahn F, Ravetch JV. Anti-inflammatory activity of immunoglobulin G resulting from Fc sialylation. Science (2006) 313(5787):670-3. doi:10.1126/science.1129594

88. Anthony RM, Wermeling F, Karlsson MC, Ravetch JV. Identification of a receptor required for the anti-inflammatory activity of IVIG. Proc Natl Acad Sci USA (2008) 105(50):19571-8. doi:10.1073/pnas.0810163105

89. Chen XX, Chen YQ, Ye S. Measuring decreased serum IgG sialylation: a novel clinical biomarker of lupus. Lupus (2015) 24(9):948-54. doi:10.1177/0961203315570686

90. Sondermann P, Pincetic A, Maamary J, Lammens K, Ravetch JV. General mechanism for modulating immunoglobulin effector function. Proc Natl Acad Sci USA (2013) 110(24):9868-72. doi:10.1073/pnas.1307864110

91. Washburn N, Schwab I, Ortiz D, Bhatnagar N, Lansing JC, Medeiros A, et al. Controlled tetra-Fc sialylation of IVIg results in a drug candidate with consistent enhanced anti-inflammatory activity. Proc Natl Acad Sci USA (2015) 112(11):E1297-306. doi:10.1073/pnas.1422481112 
92. Anthony RM, Nimmerjahn F, Ashline DJ, Reinhold VN, Paulson JC, Ravetch JV. Recapitulation of IVIG anti-inflammatory activity with a recombinant IgG Fc. Science (2008) 320(5874):373-6. doi:10.1126/science.1154315

93. Schwab I, Biburger M, Kronke G, Schett G, Nimmerjahn F. IVIg-mediated amelioration of ITP in mice is dependent on sialic acid and SIGNR1. Eur J Immunol (2012) 42(4):826-30. doi:10.1002/eji.201142260

94. Massoud AH, Yona M, Xue D, Chouiali F, Alturaihi H, Ablona A, et al. Dendritic cell immunoreceptor: a novel receptor for intravenous immunoglobulin mediates induction of regulatory T cells. J Allergy Clin Immunol (2014) 133(3):853-63. doi:10.1016/j.jaci.2013.09.029

95. Samsom JN, van Berkel LA, van Helvoort JM, Unger WW, Jansen W, Thepen T, et al. Fc gamma RIIB regulates nasal and oral tolerance: a role for dendritic cells. J Immunol (2005) 174(9):5279-87. doi:10.4049/jimmunol.174.9.5279

96. Guilliams M, Bruhns P, Saeys Y, Hammad H, Lambrecht BN. The function of Fcgamma receptors in dendritic cells and macrophages. Nat Rev Immunol (2014) 14(2):94-108. doi:10.1038/nri3582

97. Fiebiger BM, Maamary J, Pincetic A, Ravetch JV. Protection in antibody- and T cell-mediated autoimmune diseases by antiinflammatory IgG Fcs requires type II FcRs. Proc Natl Acad Sci USA (2015) 112(18):E2385-94. doi:10.1073/ pnas. 1505292112

98. Othy S, Topcu S, Saha C, Kothapalli P, Lacroix-Desmazes S, Kasermann F, et al. Sialylation may be dispensable for reciprocal modulation of helper T cells by intravenous immunoglobulin. Eur J Immunol (2014) 44(7):2059-63. doi:10.1002/eji.201444440

99. Guhr T, Bloem J, Derksen NI, Wuhrer M, Koenderman AH, Aalberse $\mathrm{RC}$, et al. Enrichment of sialylated IgG by lectin fractionation does not enhance the efficacy of immunoglobulin $G$ in a murine model of immune thrombocytopenia. PLoS One (2011) 6(6):e21246. doi:10.1371/journal. pone.0021246

100. Leontyev D, Katsman Y, Ma XZ, Miescher S, Kasermann F, Branch DR. Sialylation-independent mechanism involved in the amelioration of murine immune thrombocytopenia using intravenous gammaglobulin. Transfusion (2012) 52(8):1799-805. doi:10.1111/j.1537-2995.2011.03517.x

101. Campbell IK, Miescher S, Branch DR, Mott PJ, Lazarus AH, Han D, et al. Therapeutic effect of IVIG on inflammatory arthritis in mice is dependent on the Fc portion and independent of sialylation or basophils. J Immunol (2014) 192(11):5031-8. doi:10.4049/jimmunol.1301611

102. Geijtenbeek TB, Gringhuis SI. Signalling through C-type lectin receptors: shaping immune responses. Nat Rev Immunol (2009) 9(7):465-79. doi: $10.1038 /$ nri2569

103. Gringhuis SI, den Dunnen J, Litjens M, van der Vlist M, Geijtenbeek TB. Carbohydrate-specific signaling through the DC-SIGN signalosome tailors immunity to Mycobacterium tuberculosis, HIV-1 and Helicobacter pylori. Nat Immunol (2009) 10(10):1081-8. doi:10.1038/ni.1778

104. Smits HH, Engering A, van der Kleij D, de Jong EC, Schipper K, van Capel $\mathrm{TM}$, et al. Selective probiotic bacteria induce IL-10-producing regulatory $\mathrm{T}$ cells in vitro by modulating dendritic cell function through dendritic cell-specific intercellular adhesion molecule 3-grabbing nonintegrin. J Allergy Clin Immunol (2005) 115(6):1260-7. doi:10.1016/j.jaci.2005.03.036

105. Anthony RM, Wermeling F, Ravetch JV. Novel roles for the IgG Fc glycan. Ann N Y Acad Sci (2012) 1253:170-80. doi:10.1111/j.1749-6632.2011.06305.x

106. Pincetic A, Bournazos S, DiLillo DJ, Maamary J, Wang TT, Dahan R, et al. Type I and type II Fc receptors regulate innate and adaptive immunity. Nat Immunol (2014) 15(8):707-16. doi:10.1038/ni.2939

107. Crispin M, Yu X, Bowden TA. Crystal structure of sialylated IgG Fc: implications for the mechanism of intravenous immunoglobulin therapy. Proc Natl Acad Sci USA (2013) 110(38):E3544-6. doi:10.1073/pnas.1310657110

108. Yu X, Vasiljevic S, Mitchell DA, Crispin M, Scanlan CN. Dissecting the molecular mechanism of IVIg therapy: the interaction between serum IgG and DC-SIGN is independent of antibody glycoform or Fc domain. J Mol Biol (2013) 425(8):1253-8. doi:10.1016/j.jmb.2013.02.006

109. Kasermann F, Boerema DJ, Ruegsegger M, Hofmann A, Wymann S, Zuercher AW, et al. Analysis and functional consequences of increased Fab-sialylation of intravenous immunoglobulin (IVIG) after lectin fractionation. PLoS One (2012) 7(6):e37243. doi:10.1371/journal.pone.0037243

110. Yamazaki S, Dudziak D, Heidkamp GF, Fiorese C, Bonito AJ, Inaba K, et al. CD8+ CD205+ splenic dendritic cells are specialized to induce Foxp3+ regulatory T cells. J Immunol (2008) 181(10):6923-33. doi:10.4049/ jimmunol.181.10.6923

111. Tha-In T, Metselaar HJ, Bushell AR, Kwekkeboom J, Wood KJ. Intravenous immunoglobulins promote skin allograft acceptance by triggering functional activation of CD4+Foxp3+ T cells. Transplantation (2010) 89(12):1446-55. doi:10.1097/TP.0b013e3181dd6bf1

112. Becker C, Kubach J, Wijdenes J, Knop J, Jonuleit H. CD4-mediated functional activation of human CD4+CD25+ regulatory T cells. Eur J Immunol (2007) 37(5):1217-23. doi:10.1002/eji.200636480

113. Pashov A, Bellon B, Kaveri SV, Kazatchkine MD. A shift in encephalitogenic $\mathrm{T}$ cell cytokine pattern is associated with suppression of EAE by intravenous immunoglobulins (IVIg). Mult Scler (1997) 3(2):153-6. doi: $10.1177 / 135245859700300218$

114. Pashov A, Dubey C, Kaveri SV, Lectard B, Huang YM, Kazatchkine MD, et al. Normal immunoglobulin $\mathrm{G}$ protects against experimental allergic encephalomyelitis by inducing transferable $\mathrm{T}$ cell unresponsiveness to myelin basic protein. Eur J Immunol (1998) 28(6):1823-31. doi:10.1002/ (SICI)1521-4141(199806)28:06<1823::AID-IMMU1823>3.0.CO;2-F

115. Andersson U, Bjork L, Skansen-Saphir U, Andersson J. Pooled human IgG modulates cytokine production in lymphocytes and monocytes. Immunol Rev (1994) 139:21-42. doi:10.1111/j.1600-065X.1994.tb00855.x

116. Maddur MS, Vani J, Hegde P, Lacroix-Desmazes S, Kaveri SV, Bayry J. Inhibition of differentiation, amplification, and function of human TH17 cells by intravenous immunoglobulin. J Allergy Clin Immunol (2011) 127(3):e1-7. doi:10.1016/j.jaci.2010.12.1102

117. Cooper N, Heddle NM, Haas M, Reid ME, Lesser ML, Fleit HB, et al. Intravenous (IV) anti-D and IV immunoglobulin achieve acute platelet increases by different mechanisms: modulation of cytokine and platelet responses to IV anti-D by FcgammaRIIa and FcgammaRIIIa polymorphisms. Br J Haematol (2004) 124(4):511-8. doi:10.1111/j.1365-2141.2004.04804.x

118. Mouzaki A, Theodoropoulou M, Gianakopoulos I, Vlaha V, Kyrtsonis MC, Maniatis A. Expression patterns of Th1 and Th2 cytokine genes in childhood idiopathic thrombocytopenic purpura (ITP) at presentation and their modulation by intravenous immunoglobulin G (IVIg) treatment: their role in prognosis. Blood (2002) 100(5):1774-9.

119. Wei S, Kryczek I, Zou W. Regulatory T-cell compartmentalization and trafficking. Blood (2006) 108(2):426-31. doi:10.1182/blood-2006-01-0177

120. Iellem A, Mariani M, Lang R, Recalde H, Panina-Bordignon P, Sinigaglia F, et al. Unique chemotactic response profile and specific expression of chemokine receptors CCR4 and CCR8 by CD4(+)CD25(+) regulatory T cells. J Exp Med (2001) 194(6):847-53. doi:10.1084/jem.194.6.847

121. Matsushima H, Takashima A. Bidirectional homing of Tregs between the skin and lymph nodes. J Clin Invest (2010) 120(3):653-6. doi:10.1172/JCI42280

122. Tha-In T, Metselaar HJ, Tilanus HW, Groothuismink ZM, Kuipers EJ, de Man $\mathrm{RA}$, et al. Intravenous immunoglobulins suppress T-cell priming by modulating the bidirectional interaction between dendritic cells and natural killer cells. Blood (2007) 110(9):3253-62. doi:10.1182/blood-2007-03-077057

Conflict of Interest Statement: The authors declare that the research was conducted in the absence of any commercial or financial relationships that could be construed as a potential conflict of interest.

Copyright (c) 2015 Kaufman, Massoud, Dembele, Yona, Piccirillo and Mazer. This is an open-access article distributed under the terms of the Creative Commons Attribution License (CC BY). The use, distribution or reproduction in other forums is permitted, provided the original author(s) or licensor are credited and that the original publication in this journal is cited, in accordance with accepted academic practice. No use, distribution or reproduction is permitted which does not comply with these terms. 